\title{
When Are Learning Analytics Ready and What Are They Ready For
}

\author{
Alyssa Wise, Simon Knight, Xavier Ochoa \\ Editors-in-Chief - Journal of Learning Analytics - jla.editorial@gmail.com
}

\section{What Kinds of Impact Do We Want to Have?}

Learning Analytics, as a field of inquiry and community of practice, is distinct in the way that it brings together in shared pursuit the research and practice of a particular kind of educational technology. At times this relationship approaches symbiosis: the annual Learning Analytics and Knowledge (LAK) conference offers opportunities to learn both about the latest theoretical, methodological, and technological innovations as well as challenges and effective strategies for using such innovations to support learning in real world contexts. At other times, we feel pulled in multiple directions by the different priorities of each endeavor. Research is first and foremost concerned with advancing the state of the field by building knowledge, theories, techniques and tools with generalizable implications. Practice is primarily focused on action and implementation to have a positive impact on local real world learning contexts. While these aims are not unrelated, they often offer quite different answers to the question of when a learning analytics application is ready to be used in an authentic educational setting with actual learners (and real consequences). At the extreme pole of a research perspective, there is always the temptation to try one more way to optimize an analytic (have we considered all possible features, tried all appropriate algorithms, tweaked all available hyper-parameters, explored all possible visualizations etc.). But from the perspective of practice with pressing problems to address, a tool that is available and sufficiently optimised is better than a perfect but unavailable one. The ultimate goal is increased impact on learning not simply improved model accuracy. Of course, as a scholarly pursuit, the field of learning analytics does not seek to only develop and implement innovative data-based technologies, but also develop a knowledge base around them. Thus the key question is how can we make a difference in the world while also engaging in a rigorous knowledge producing process?

\section{Technologies in the World and Design Sciences}

There is a danger that taking an extreme "pure research" perspective will lead to considering implementation of learning analytics as simply a final step, after the real work is done. In other words, there is an implicit assumption in such an approach that analytics can be effectively developed and tested in a controlled lab environment and that only when they are sufficiently optimized can and should they be rolled out into the world. However, there is a long history of educational technologies that have not delivered on the promise of impact on learning (Cuban, 1986), and even where effects seem clear in highly controlled environments, they do not necessarily translate in the messy contexts of real world learning. Moreover, the work of translating and implementing technologies for impact is often not smooth, and as such this implementation space is a site for research in its own right. This is because the use of educational technologies - including learning analytics - is not determined solely by features of the technology itself. The ways that technologies are used and integrated into learning results from the complex interplay between stakeholders, their learning situations, and the affordances of the new tools (Cuban, 2009; Gibson, 1986). Important issues related to privacy and ethics may also not surface until learning analytics are applied "in the wild." Conversely, the "pure application" perspective places learning analytics at risk of becoming simply an operational tool, instead of a science in its own right. Too great a focus on the concerns of individual contexts can limit the ways in which learning analytics contribute to generalizable knowledge. It is therefore critical that practical implementations both draw on and contribute back to a common knowledge base. Without such bi-directional efforts, the context of institutional demands may lead to learning analytics systems that are built and put into operation on extremely rapid time-scales, without informing and being informed by a rich body of research knowledge.

Design-based research is a methodological approach adopted in the Learning Sciences to simultaneously advance theory and impact practice by studying designed learning experiences in authentic educational settings (2003). It is concerned with not only if, but how, why, and under what conditions an educational innovation is effective for learning. Progress (in both theory building and improvement of the innovation itself) occurs through iterative cycles as a design is created to instantiate theoretical ideas about how learning occurs and can be supported, then enacted in a real-world context, with the process of learning and its concomitant outcomes analyzed to inform, refine and revise the theory and corresponding design (Barab, 2014). 
Such an approach holds promise for learning analytics research to build theory and generate impact in mutually supportive ways. Key tenets of design sciences often point to theories of action for their designed artifacts, consider the involvement of the end user as central in the creation and testing of an innovation, with its intended context of use as a core consideration in the design process rather than an afterthought. Whether (and if so, how) these principles should guide the development of learning analytics is an important question for the community to address. Such issues of our identity as a field and how we conduct learning analytics research and practice are important ones which we will continue to consider moving forward.

\section{JLA 2018 in Review}

During 2018, the articles published in the Journal of Learning Analytics have collectively reflected the efforts of our field to find the right combination of rigorousness and educational relevance in our work. This is particularly evident when examining the foci of our special sections.

We began the year with the conclusion of the two-part special section on Temporal Analyses of Learning Data (Chen, Knight, \& Wise, 2018). This section explored why and how Learning Analytics should include and embrace considerations of time as a way to produce more relevant and impactful results. The articles in this special section tackled and exploited complex temporal data in real-world applications for learning. This is a feature of learning that has been understudied in educational research, in part due to a paucity of methodological techniques for its analysis. These papers in learning analytics thus help to connect to authentic learning contexts, where the reality of temporal concerns in student learning is very clear.

In contrast, the second special section of the year focused on Methodological Choices in Learning Analytics (Bergner, Gray, \& Lang, 2018). This section took a critical and detailed look at how Learning Analytics research is conducted. Several methodological recommendations are identified in its articles and the section editorial provides a cautionary perspective for multidisciplinary fields, such as Learning Analytics, in drawing on analytic methods that entail multiple assumptions about data inputs and interpretation. This special section highlights the need to consider research rigour alongside practical development in producing generalizable knowledge.

Concluding this year, our final special section contains invited articles from the LAK 2018 conference (Ochoa \& Merceron, 2018), providing a good indicator of the variety of topics at the cutting edge of the field. These topics range from specific solutions to learning problems, such as the analysis of student gaze to improve programming skills (Mangaroska, Sharma, Giannakos, Trætteberg, \& Dillenbourg, 2018), to more generalizable techniques that could be used across institutions such as co-enrollment analysis (Brown, DeMonbrun, \& Teasley, 2018), to high-level conceptual discussions around topics such as Learning Analytics policy frameworks (Tsai et al., 2018). All the selected papers offer a sample of how high-quality research can also produce impactful solutions for learners, instructors and administrators.

Supplementing these special sections, the journal has published other contributions in our traditional Research Papers (RP) section and our newly created Dataset and Tools (DnT) section. The RP section continues its focus on new theoretical and applied research with papers addressing prediction of student outcomes (O'Connell, 2018), interaction with videos in MOOCs (Atapattu \& Falkner, 2018), actionable insight in Learning Analytics (Jørnø \& Gynther, 2018) and dialog analysis in Intelligent Tutoring Systems (Wolfe, Widmer, Torrese, \& Dandignac, 2018). The DnT section disseminates more technical work with a focus on data, systems, and processes that can be used to facilitate the work of others in the field. The first DnT paper (Muslim, Chatti, Bashir, Varela, \& Schroeder, 2018) concretely addressed Open Learning Analytics, a topic long discussed in the field in theoretical terms, by proposing a technical framework for implementation. The DnT paper published in this issue (Pardo et al., 2018) describes OnTask, a system deployed to provide personalized feedback at scale. We encourage future DnT submission to continue this new tradition of useful contributions to learning analytics research and practice.

\section{Supporting Dialogue for Impact: Notes for Practice and Research}

Reading over the articles from this year it is clear that as the Learning Analytics field matures we are negotiating the balance between action, impact, theory, and technologies. To build the conversation between research and practice across different community members engaged in learning analytics work, all Journal of Learning Analytics articles now include "Structured Notes" alongside the abstract. This change mirrors that of several other journals that have recently introduced bulleted "highlights" in addition to the abstract as a way to describe the significance of the work for particular stakeholders. For research papers, these "Notes for Practice" highlight the significance of the research for practical contexts, including how the findings may create concrete implications for learning analytics implementations. For practical reports, the "Notes for Research" highlight the significance of the work for researchers, including how the findings may contextualise existing findings or open up new avenues requiring future research. These notes comprise short bulleted overviews, following the structure indicated in the journal Author Guidelines pages. Prospective authors can review prior examples in framing their own notes, for example Epp, Phirangee, and Hewitt (2017). 


\section{Ensuring the Continued High Ethical Standards of the Journal}

To assure best practice around transparency and publication ethics (for example, those outlined by COPE: the Committee on Publication Ethics) the journal has also introduced and clarified a number of our policies. In particular, our authors and reviewers will have noticed that the journal has now moved to a double blind review, and introduced clear guidance for ensuring manuscripts are blinded. Prospective authors should familiarise themselves with this guidance. The journal has also introduced and enforced an authorship statement and authorship guidelines that make explicit the standards expected for qualification as an author in the JLA, and requests that manuscripts with four or more authors submit a statement that outlines the contribution that each author has made to the work. These policy descriptions and the new template - which we discuss below - are intended to make our requirements clearer to the community and to ensure authors and reviewers readily have all the information they need; we welcome feedback on these changes, which can be emailed to jla.editorial@gmail.com.

\section{A New Template for the Journal}

Readers may have noticed a change to the journal's look and feel. The new template we have adopted provides a more contemporary and readable style to the articles, and incorporates information advised by the COPE recommendations. We are also pleased to announce that the new template is available in both Microsoft word and LaTeX formats to meet the needs of our diverse community. Users of the journal website may have also noticed some recent changes to the platform, as our publisher (the UTS ePress), upgraded the journal to the open OJS 3 system. We hope that this upgrade will provide our authors, reviewers and guest editors with an improved experience.

\section{Upcoming Special Sections and Contribution Opportunities}

This year we also put out calls for three new special sections. In July papers were submitted to the special section on 'Learning Analytics Tools and Datasets', specifically focused on how new techniques and datasets can help push forward the field of learning analytics research and it practical impact on learning. The deadline for submissions to the 'Human-Centred Learning Analytics: Design Frameworks, Tools and Techniques' section passed in October, with a particularly exciting focus on human-centred approaches to design of learning analytics and their role in the effective adoption and implementation of learning analytics; the core of the introduction to this editorial. Finally, prospective authors may still submit to the special section 'Beyond Cognitive Ability: Enabling Assessment of 21st Century Skills Through Learning Analytics'. This section is intended to provide a critical perspective on analysis and assessment of 21 st century skills, with a variety of theoretical, empirical, and methodological papers solicited - see the full call for details.

Prospective authors can, of course, also submit outside of the special section calls. The journal welcomes manuscripts on an ongoing basis, and we would encourage prospective authors to read the journal Focus and Scope to understand the range of submission types and their requirements. We particularly welcome proposals for special sections of the journal, and invite prospective guest editors to contact us.

Finally, we are pleased to announce a new section of the journal dedicated to providing reviews of books that are of relevance to the learning analytics community. We anticipate publishing our first reviews in 2019 and hope to publish a small number of such reviews each year. Suggestions for books that are likely to be of significance to the field can be sent to the editors at jla.editorial@gmail.com.

\section{A Thank You to Contributors, Reviewers and Guest Editors}

The editors would like to thank the authors, reviewers, and guest editors who have made, and continue to make, contributions to the journal. As editors, we are both honored and humbled to share with you the responsibility for ensuring the quality, rigor and usefulness of the contributions that are published in JLA, a core venue for distributing learning analytics research and practice.

\section{References}

Atapattu, T., \& Falkner, K. (2018). Impact of lecturer's discourse for students' video engagement: Video learning analytics case study of moocs. Journal of Learning Analytics, 5(3), 182-197. https://dx.doi.org/10.18608/jla.2018.53.12

Barab, S. (2014). Design-based research: A methodological toolkit for engineering change. In The cambridge handbook of the learning sciences, second edition. Cambridge University Press.

Bergner, Y., Gray, G., \& Lang, C. (2018). What does methodology mean for learning analytics? Journal of Learning Analytics, 5(2), 1-8. https://dx.doi.org/10.18608/jla.2018.52.1

Brown, M., DeMonbrun, M., \& Teasley, S. (2018). Conceptualizing students' concurrent course enrollment across the post-secondary curriculum using temporal analytics. Journal of Learning Analytics, 5(3), 60-72. https://dx.doi.org/10.18608/jla.2018.53.5 
Chen, B., Knight, S., \& Wise, A. F. (2018). Critical issues in designing and implementing temporal analytics. Journal of Learning Analytics, 5(1), 1-9. https://dx.doi.org/10.18608/jla.2018.53.1

Collective, D.-B. R. (2003). Design-based research: An emerging paradigm for educational inquiry. Educational Researcher, 32(1), 5-8. https://dx.doi.org/10.3102/0013189X032001005

Cuban, L. (1986). Teachers and machines: The classroom use of technology since 1920. Teachers College Press.

Cuban, L. (2009). Oversold and underused. Harvard University Press.

Gibson, J. J. (1986, September). The theory of affordances. In The ecological approach to visual perception (New Ed ed., pp. 127-143). Psychology Press.

Jørnø, R. L., \& Gynther, K. (2018). What constitutes an 'actionable insight' in learning analytics? Journal of Learning Analytics, 5(3), 198-221. https://dx.doi.org/10.18608/jla.2018.53.13

Mangaroska, K., Sharma, K., Giannakos, M., Trætteberg, H., \& Dillenbourg, P. (2018). Gaze-driven design insights to amplify debugging skills: A learner-centered analysis approach. Journal of Learning Analytics, 5(3), 98-119. https://dx.doi.org/10.18608/jla.2018.53.7

Muslim, A., Chatti, M. A., Bashir, M. B., Varela, O. E. B., \& Schroeder, U. (2018). A modular and extensible framework for open learning analytics. Journal of Learning Analytics, 5(1), 92-100. https://dx.doi.org/10.18608/jla.2018.51.7

Ochoa, X., \& Merceron, A. (2018). Quantitative and qualitative analysis of the learning analytics and knowledge conference 2018. Journal of Learning Analytics, 5(3), 154-166. https://dx.doi.org/10.18608/jla.2018.53.10

O'Connell, K. (2018). Student ability best predicts final grade in a college algebra course. Journal of Learning Analytics, 5(3), 167-181. https://dx.doi.org/10.18608/jla.2018.53.11

Pardo, A., Bartimote, K., Buckingham Shum, S., Dawson, S., Gao, J., Gašević, D., ... Vigentini, L. (2018). Ontask: Delivering data-informed, personalized learning support actions. Journal of Learning Analytics, 5(3), $235-249$. https://dx.doi.org/10.18608/jla.2018.53.15

Tsai, Y.-S., Moreno-Marcos, P. M., Jivet, I., Scheffel, M., Tammets, K., Kollom, K., \& Gašević, D. (2018). The sheila framework: informing institutional strategies and policy processes of learning analytics. Journal of Learning Analytics, 5(3), 5-20. https://dx.doi.org/10.18608/jla.2018.53.2

Wolfe, C., Widmer, C., Torrese, C., \& Dandignac, M. (2018). A method for automatically analyzing intelligent tutoring system dialogues with coh-metrix. Journal of Learning Analytics, 5(3), 222-234. https://dx.doi.org/10.18608/jla.2018.53.14 